\title{
THERMAL CONDUCTIVITY AND THERMAL DIFFUSIVITY OF BIODIESEL AND BIOETHANOL SAMPLES
}

\author{
Monika BOŽIKOVÁ, Peter HLAVÁČ
}

Slovak University of Agriculture in Nitra, Slovakia

\begin{abstract}
This article deals with thermal properties of selected biodiesel and bioethanol samples (biodiesel No 1, No 2 and bioethanol No 1, No 2). Biodiesel is renewable fuel that can be manufactured from vegetable oils, animal fats, or recycled restaurant grease for use in diesel vehicles. Biodiesel's physical properties are similar to those of petroleum diesel, but it is a cleaner-burning alternative fuel. Ethanol $\left(\mathrm{CH}_{3} \mathrm{CH}_{2} \mathrm{OH}\right)$ is a clear liquid. Also known as ethyl alcohol, grain alcohol, and EtOH, the molecules in this fuel contain a hydroxyl group $\left(\mathrm{OH}^{-}\right)$bonded to a carbon atom. Ethanol is made of the same chemical compound regardless of whether it is produced from starch and sugar-based feedstocks, such as corn grain, sugar cane, etc. The hot wire method was used for thermal parameters measurements. The experiment is based on measuring the temperature rise vs. time evaluation of an electrically heated wire embedded in the tested material. Thermal conductivity is derived from the resulting change in temperature over a known time interval. For two samples of biodiesel and two samples of bioethanol, there were determined basic thermophysical parameters thermal conductivity and thermal diffusivity. Two series of measurements were made for each sample of biodiesel and bioethanol. In the first series, there were measured the thermal conductivity and thermal diffusivity at constant room temperature $20^{\circ} \mathrm{C}$. Every thermophysical parameter was measured 10 times for each sample. The results were statistically processed. In the second series of measurements, there were measured the relations of thermal conductivity and thermal diffusivity to temperature in temperature range $20-29^{\circ} \mathrm{C}$. It was evident from results that all measured dependencies are nonlinear. Polynomial functions described by polynomial coefficients were obtained for both thermophysical parameters. The type of function was selected according to statistical evaluation based on the coefficient of determination for every thermophysical parameter graphical dependency. All obtained results are presented in Figures 1-4 and in Tables 1-4. The results of thermophysical parameters measurements of biodiesel and bioethanol could be compared with the values presented in literature.
\end{abstract}

Keywords: temperature, thermal conductivity, thermal diffusivity, biodiesel, bioethanol

Thermophysical properties such as temperature, thermal conductivity and thermal diffusivity are very important properties. Especially thermal conductivity and thermal diffusivity are properties that characterize the heat transfer behaviour, and many times the quality of the finished product depends on the correct setting of temperature respectively the time course of temperature. Accurate values of these properties are critical for practical design as well as theoretical studies and analysis, especially in the fields of heat transfer and thermal processing (Božiková and Hlaváč, 2010). The knowledge of thermophysical properties of materials is especially significant in the context of biobased materials which are often mechanically or thermally processed respectively for materials exposed to natural changes of temperature conditions. Due to the previous reasons, the presented contribution deals with the problem of measuring the biodiesel and bioethanol as materials of biological origin.

\section{Material and methods}

Biodiesel composition - biodiesel is made in a chemical process called transesterification where organically derived oils (vegetable oils, animal fats and recycled restaurant greases) are combined with alcohol (usually methanol) and chemically altered to form fatty esters such as methyl ester. The biomass-derived esters can be blended with conventional diesel fuel or used as a neat fuel (100\% biodiesel). The process results in two products - methyl esters (the chemical name for biodiesel) and glycerine. Biodiesel is a domestically produced, renewable fuel that can be manufactured from vegetable oils, animal fats, or recycled restaurant grease for use in diesel vehicles. Biodiesel's physical properties are similar to those of petroleum diesel, but it is a cleaner-burning alternative fuel. Using biodiesel in place of petroleum diesel reduces emissions. It is non-toxic and biodegradable. Biodiesel is a liquid fuel made up of fatty acid alkyl esters, fatty acid methyl esters, or long-chain mono-alkyl esters. Like petroleum diesel, biodiesel is used to fuel compression-ignition engines, which run on petroleum diesel (Biodiesel, 2012).

The principle fuel used as a petrol substitute for road transport vehicles is bioethanol. Bioethanol fuel is mainly produced by the sugar fermentation process, although it can also be manufactured by the chemical process of reacting ethylene with steam. The main sources of sugar required to produce ethanol come from fuel or energy crops. These crops are grown specifically for energy use and include corn, maize and wheat crops, waste straw, willow and popular trees, sawdust, reed canary grass, cord grasses, artichoke, myscanthus and sorghum plants. There is also ongoing research and development into the use of municipal solid wastes to produce ethanol fuel.

Ethanol or ethyl alcohol $\left(\mathrm{C}_{2} \mathrm{H}_{5} \mathrm{OH}\right)$ is a clear colourless liquid; it is biodegradable, low in toxicity and causes little environmental pollution when spilt. Ethanol burns to produce carbon dioxide and water. Ethanol is a high octane 
fuel and has replaced lead as an octane enhancer in petrol. By blending ethanol with gasoline we can also oxygenate the fuel mixture so it burns more completely and reduces polluting emissions. Ethanol fuel blends are widely sold in the United States. The most common blend is $10 \%$ ethanol and $90 \%$ petrol (E10). Vehicle engines require no modifications to run on E10 and vehicle warranties are unaffected also. Only flexible fuel vehicles can run on up to $85 \%$ ethanol and $15 \%$ petrol blends (E85) (Bioethanol, 2013).

The measuring of thermal parameters was performed by a simplified transient hot wire (HW) technique. The simplified HW method is a technique based on the measurement of the temperature rise of a linear heat source (hot wire) embedded in the tested material (Assael et al., 2008; Persons and Mulligan, 1978; Kadjo et al., 2008). For an infinitely long metallic wire (length/radius ratio $>>200$ ) heated at time $t>0$ with a constant heat flux per length unit $q$ and immersed in an infinite homogeneous medium (thermal conductivity and diffusivity: $\lambda$ and $a$ with uniform initial temperature), the temperature rise $\lambda \Delta T(t)$ of the wire is given by Equation (1) (Carslaw and Jaeger, 1959):

$$
\Delta T(t)=\frac{q}{4 \pi \lambda} \ln \frac{4 F_{0}}{C}
$$

with $C=e^{\gamma}=1.781$

where:

$\gamma \quad$ - Euler's constant $(\gamma=0.5772)$

$F_{0} \quad$ - the Fourier number defined by

$$
F_{0}=\frac{a t}{r_{0}^{2}}
$$

Equation (1) is the analytical solution of an ideal thermal conductive model valid for $F_{0}>>1$ and without convective transfers (Healy et al., 1976; Wakeham and Nagashima, 1991; Tavman, 1996). From this ideal model and with known $q$ values, thermal conductivity can be calculated by Equation (3):

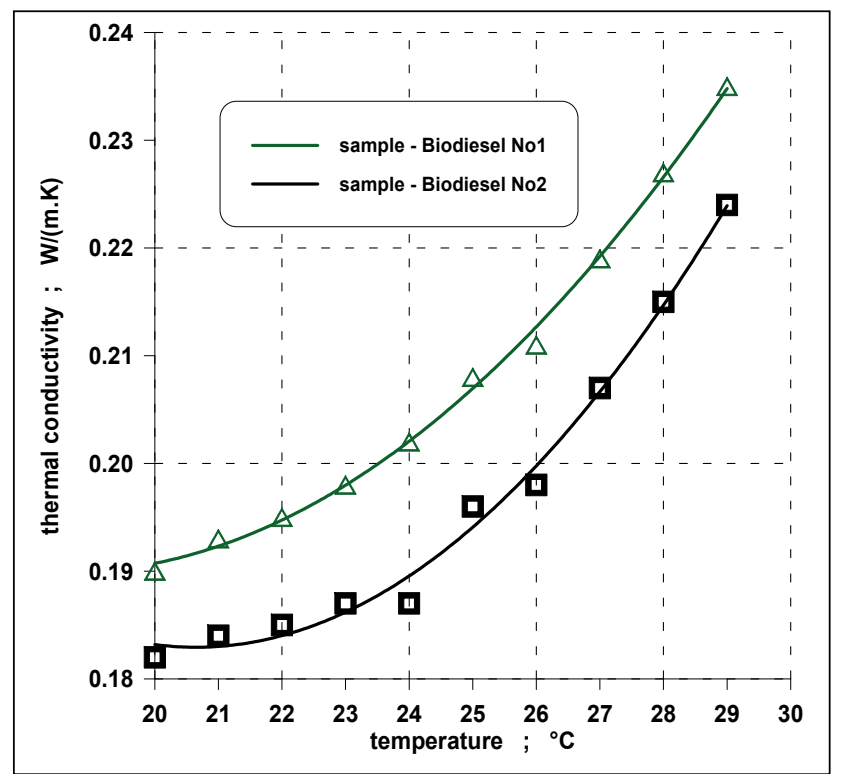

$$
\lambda=\frac{q}{4 \pi}\left(\frac{d T}{d(\ln t)}\right)^{-1}
$$

where:

$d T / d(\ln t)$ - a numerical constant deduced from experimental data for $t$ values which satisfy the condition $F_{0}>>1$

For practical applications of the HW method, wire and material sample dimensions, among other ideal model hypotheses, are finite and deviations from the ideal model have then to be evaluated. In fact, the $e(t)$ answer to the wire heating $\Delta T(t)$ resultant of the Joule effect due to electric current is:

$$
R(t)=R_{0}\left(1+\beta_{0}\left(T(t)-T_{0}\right)\right)
$$

where:

$R(t)$ - the instantaneous electrical resistance of the wire

Ro - the resistance of the wire at the $T_{0}$ reference temperature

$\beta_{0} \quad$ - the temperature coefficient of the wire at $22^{\circ} \mathrm{C}$

Taking into account (3) and (4), thermal conductivity $\lambda$ can be calculated as follows:

$$
\lambda=\frac{q R_{0} \beta_{0} i}{4 \pi}\left(\frac{d e(t)}{d(\ln t)}\right)^{-1}
$$

where:

$d e(t) / d(\ln t)$ - a numerical constant deduced from the experimental data and from the linear part of the $e(t)=f(\ln (t))$ curve (Carslaw and Jaeger, 1959).

\section{Results and discussion}

Samples of biodiesel and bioethanol were stored at laboratory temperature 24 hours before the measurement. Measurements were performed in the temperature interval from laboratory temperature to $29{ }^{\circ} \mathrm{C}$. Dependencies of thermal conductivity and thermal diffusivity on temperature were examined. Relations of thermal

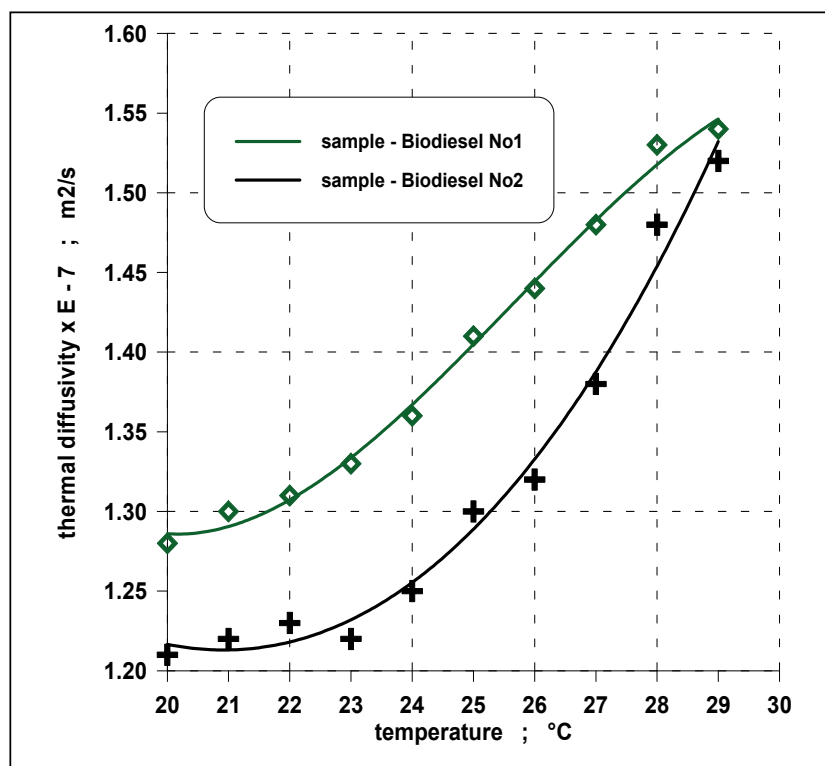

Figure 1, 2 Relations of thermal conductivity and thermal diffusivity to temperature for samples - Biodiesel No 1 and No 2 
Table 1 Statistical evaluation of the measured values for thermal conductivity of biodiesel and bioethanol samples

\begin{tabular}{|c|c|c|c|c|}
\hline \multicolumn{5}{|c|}{ Statistical evaluation of the measured values for thermal conductivity at $20^{\circ} \mathrm{C}$} \\
\hline \multirow[t]{2}{*}{ Sample } & \multicolumn{2}{|c|}{ Biodiesel } & \multicolumn{2}{|c|}{ Bioethanol } \\
\hline & No 1 & No 2 & Polar & SK \\
\hline Arithmetic average in $\mathrm{W} \cdot \mathrm{m}^{-1} \cdot \mathrm{K}^{-1}$ & 0.190 & 0.182 & 0.102 & 0.114 \\
\hline Standard deviation in W. $\mathrm{m}^{-1} \cdot \mathrm{K}^{-1}$ & \pm 0.015 & \pm 0.014 & \pm 0.024 & \pm 0.033 \\
\hline Probable error in W. $\mathrm{m}^{-1} \cdot \mathrm{K}^{-1}$ & \pm 0.006 & \pm 0.004 & \pm 0.001 & \pm 0.002 \\
\hline Relative probable error in \% & \pm 3.51 & \pm 2.20 & \pm 0.98 & \pm 1.75 \\
\hline \multicolumn{5}{|c|}{ Statistical evaluation of thermal conductivity graphical dependencies for temperature range $20-29{ }^{\circ} \mathrm{C}$} \\
\hline Type of function & \multicolumn{4}{|c|}{ polynomial function } \\
\hline Arithmetic average of values $t$ & \multicolumn{4}{|c|}{$24.5^{\circ} \mathrm{C}$} \\
\hline Arithmetic average of values $\lambda$ in W. $\mathrm{m}^{-1} . \mathrm{K}^{-1}$ & 0.208 & 0.197 & 0.114 & 0.102 \\
\hline Minimum value in $\mathrm{W} \cdot \mathrm{m}^{-1} \cdot \mathrm{K}^{-1}$ & 0.190 & 0.182 & 0.080 & 0.180 \\
\hline Maximum value in $\mathrm{W} \cdot \mathrm{m}^{-1} \cdot \mathrm{K}^{-1}$ & 0.235 & 0.224 & 0.196 & 0.067 \\
\hline \multicolumn{5}{|c|}{ Polynomial coefficients } \\
\hline degree 0 & 0.33 & 0.43 & 1.59 & 1.52 \\
\hline degree 1 & -0.015 & -0.024 & -0.110 & -0.104 \\
\hline degree 2 & 0.00041 & 0.00059 & 0.00201 & 0.0019 \\
\hline \multicolumn{5}{|c|}{ Coefficient of determination (R-squared) } \\
\hline degree 0 & 0 & 0 & 0 & 0 \\
\hline degree 1 & 0.985 & 0.954 & 0.927 & 0.937 \\
\hline degree 2 & 0.991 & 0.976 & 0.980 & 0.994 \\
\hline
\end{tabular}

conductivity and thermal diffusivity to temperature for samples of biodiesel are presented in Figures 1 and 2. There are shown dependencies for two different types of biodiesel samples. Identical dependencies between thermophysical parameters and temperature were obtained for two types of bioethanol samples - Figures 3 and 4.

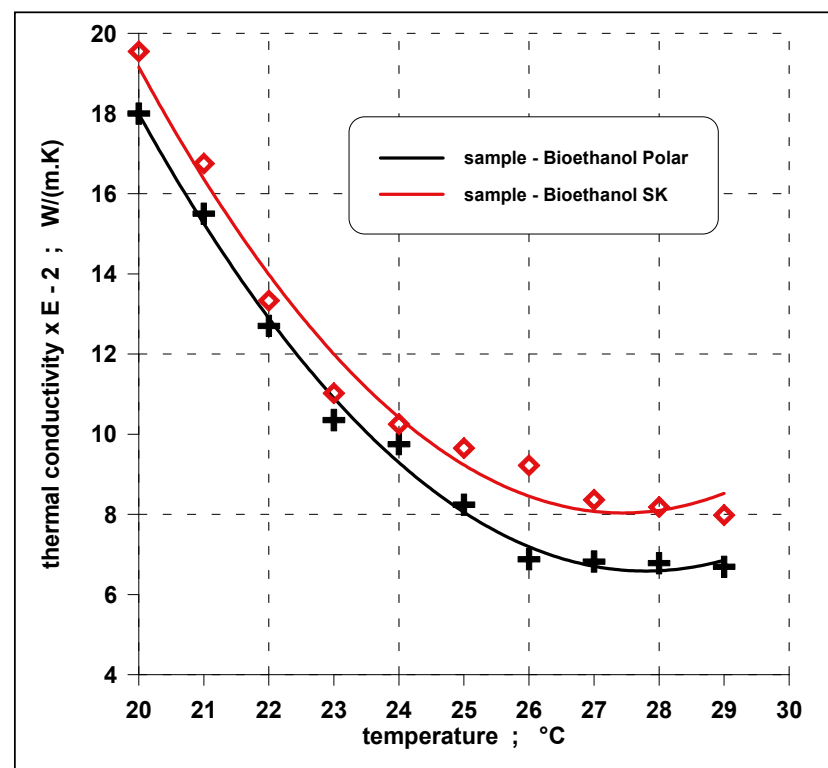

\section{Results and conclusions for biodiesel samples}

The sample marked biodiesel No 1 had higher thermal conductivity and thermal diffusivity. In general, both biodiesel samples had similar values of thermal conductivity, biodiesel No $1-0.190 \mathrm{~W} \cdot \mathrm{m}^{-1} \cdot \mathrm{K}^{-1}$ and biodiesel No $2-0.182 \mathrm{~W} \cdot \mathrm{m}^{-1} \cdot \mathrm{K}^{-1}$. The thermal diffusivity values for both samples were obtained

Figure 3,4 Relations of thermal conductivity and thermal diffusivity to temperature for samples - Bioethanol Polar and Bioethanol SK 
Table 2 Statistical evaluation of the measured values for thermal diffusivity of biodiesel and bioethanol samples

\begin{tabular}{|c|c|c|c|c|}
\hline \multicolumn{5}{|c|}{ Statistical evaluation of the measured values for thermal diffusivity at $20^{\circ} \mathrm{C}$} \\
\hline & \multicolumn{2}{|c|}{ Biodiesel } & \multicolumn{2}{|c|}{ Bioethanol } \\
\hline & No 1 & No 2 & No 1 & No 2 \\
\hline Arithmetic average, $\times 10^{-7} \mathrm{~m}^{2} \cdot \mathrm{s}^{-1}$ & 1.280 & 1.210 & 1.010 & 0.912 \\
\hline Standard deviation, $\times 10^{-7} \mathrm{~m}^{2} \cdot \mathrm{s}^{-1}$ & \pm 0.107 & \pm 0.113 & \pm 0.028 & \pm 0.031 \\
\hline Probable error, $\times 10^{-7} \mathrm{~m}^{2} \cdot \mathrm{s}^{-1}$ & \pm 0.012 & \pm 0.016 & \pm 0.0012 & \pm 0.0017 \\
\hline Relative probable error, \% & \pm 0.94 & \pm 1.32 & \pm 0.57 & \pm 0.84 \\
\hline \multicolumn{5}{|c|}{ Statistical evaluation of thermal diffusivity graphical dependencies for temperature range $20-29^{\circ} \mathrm{C}$} \\
\hline Type of function & \multicolumn{4}{|c|}{ polynomial function } \\
\hline Arithmetic average of values $t$ & \multicolumn{4}{|c|}{$24,5^{\circ} \mathrm{C}$} \\
\hline Arithmetic average of values $a, \times 10^{-7} \mathrm{~m}^{2} \cdot \mathrm{s}^{-1}$ & 1.404 & 1.313 & 1.404 & 1.313 \\
\hline Minimum value, $\times 10^{-7} \mathrm{~m}^{2} \cdot \mathrm{s}^{-1}$ & 1.28 & 1.21 & 1.28 & 1.21 \\
\hline Maximum value, $\times 10^{-7} \mathrm{~m}^{2} \cdot \mathrm{s}^{-1}$ & 1.59 & 1.52 & 1.59 & 1.52 \\
\hline \multicolumn{5}{|c|}{ Polynomial coefficients } \\
\hline degree 0 & 7.824 & 2.294 & 271.168 & 148.066 \\
\hline degree 1 & -0.827 & -0.067 & -42.67 & -22.052 \\
\hline degree 2 & 0.0338 & -0.00103 & 2.514 & 1.234 \\
\hline degree 3 & -0.00044 & 0.00084 & -0.0657 & -0.03069 \\
\hline degree 4 & - & - & 0.00064 & 0.00029 \\
\hline \multicolumn{5}{|c|}{ Coefficient of determination (R-squared) } \\
\hline degree 0 & 0 & 0 & 0 & 0 \\
\hline degree 1 & 0.973 & 0.965 & 0.955 & 0.955 \\
\hline degree 2 & 0.988 & 0.986 & 0.958 & 0.968 \\
\hline degree 3 & 0.995 & 0.986 & 0.965 & 0.992 \\
\hline degree 4 & - & - & 0.975 & 0.995 \\
\hline
\end{tabular}

at $20^{\circ} \mathrm{C}$, i.e. biodiesel No $1-1.404 .10^{-7} \mathrm{~m}^{2} \cdot \mathrm{s}^{-1}$ and biodiesel No $2-1.313 .10^{-7} \mathrm{~m}^{2} . \mathrm{s}^{-1}$. The following statistical data were calculated for all parameters: arithmetic average, standard deviation from arithmetic average, probable error and relative probable error in percentage. The highest relative probable error in \% was observed in the measurement of thermal conductivity for sample No 1 , which was $\pm 3.51 \%$. The lowest probable error in $\%$ was obtained in the measurement of thermal diffusivity for sample No $1-0.94 \%$. Graphical dependences are presented in Figures 1 and 2. Each point of graphical dependence is the arithmetic average obtained of ten repetitive experiments for each temperature in the temperature range from $20{ }^{\circ} \mathrm{C}$ to $29^{\circ} \mathrm{C}$. The temperature dependence of thermal conductivity can be described by polynomial functions of the third degree. The presented results showed that all graphical dependencies have relatively high coefficients of determination, which were from 0.954 to 0.998 .

The obtained results can be compared only to the thermal conductivity values of biodiesel, where literature references indicate the range from $0.125 \mathrm{~W} \cdot \mathrm{m}^{-1} \cdot \mathrm{K}^{-1}$ to $0.141 \mathrm{~W} \cdot \mathrm{m}^{-1} \cdot \mathrm{K}^{-1}$. The thermal diffusivity values of biodiesel samples are considered as one of the benefits of this research.

\section{Results and conclusions for bioethanol samples}

Two samples were measured in the group of bioethanol. One sample was made in Slovakia (sample marked as Bioethanol SK - No 1), and the second sample Bioethanol Polar - No 2 was made in Germany. As in the previous experiments, we carried out two series of measurements. The results of the first series are presented in Tables 1 and 2. It is evident from graphical dependencies that increasing temperature had an opposite influence on thermal conductivity and diffusivity, so dependencies had decreasing progresses (Figure 3 and 4). From the mathematic view, dependencies can be described by polynomial functions. For thermal conductivity it is the polynomial function of the second degree and for thermal diffusivity it is the polynomial function of fourth degree which had the highest coefficients of determination.

\section{Conclusion}

The thermophysical properties of biodiesel and bioethanol samples were measured and analysed in this paper. The effect of temperature or storage temperature on used biodiesel and bioethanol samples was investigated. Thermophysical parameters of materials depend mostly on its composition. The thermal conductivity and thermal 
diffusivity of the samples was measured by the digital thermal analyser Isomet 2104 the principle of which is based on the simplified hot wire method. The temperature dependencies of biodiesel thermal conductivity and thermal diffusivity had an increasing polynomial shape (Figures 1,2), and the temperature dependencies of the same thermal parameters for bioethanol samples had a decreasing polynomial shape for all measurements (Figure $3,4)$. The coefficients of determination are very high in all measurements, approximately in range 0.927-0.998 (Table 1 and 2). On the base of presented results of thermophysical parameters measurements, it is clear that it is necessary to have knowledge about thermophysical parameters during temperature changes because temperature is one of the most important factors which determine the quality of materials.

\section{References}

ASSAEL, M. J. - ANTONIADIS, K. D. - WU, J. 2008. New measurements of the thermal conductivity of PMMA, BK7, and Pyrex 7740 up to $450 \mathrm{~K}$. In International Journal of Thermophysics, vol. 29, no. 4, pp. 1257-1266.

BIODIESEL. 2012. [online]. [Retrieved 2012-6-20]. Retrieved from: <http://www.habmigern2003.info/biogas/Biodiesel.html>

BIOETHANOL, CTBE. 2012. [online]. [Retrieved 2012-6-23]. Retrieved from: <http://www.bioetanol.org.br/english/interna/ index.php?chave $=$ bioethanol $>$

BOŽIKOVÁ, M. - HLAVÁČ, P. 2010. Selected physical properties of agricultural and food products (scientific monograph). Nitra : SUA, 2010. 178 p.
CARSLAW, H. S. - JAEGER, J. C. 1959. Conduction of heat in solids. London: Oxford University Press, 1959. $510 \mathrm{p}$.

HEALY, J. J. - de GROOT, J. J. - KESTIN, J. 1976. The theory of the transient hot-wire method for measuring thermal conductivity. In Physica B+C, vol. 82, 1976, no. 2, pp. 392-408.

KADJO, A. - GARNIER, J. P. - MAYE, J. P. - MARTEMIANOV, S. 2008. A new transient two-wire method for measuring the thermal diffusivity of electrically conducting and highly corrosive liquids using small samples. In International Journal of Thermophysics, vol. 29, 2008. no. 4, pp. 1267-1277.

PARSONS, J. R. - MULLIGAN, J. C. 1978. Measurement of the properties of liquids and gases using a transient hot-wire technique. In Review of Scientific Instruments, vol. 49, 1978. no. 10, pp. $1460-1463$.

TAVMAN, I. H. 1996. Effective thermal conductivity of granular porous materials. In International Communications in Heat and Mass Transfer, vol. 23, 1996. no. 2, pp. 169-176.

WAKEHAM, W. A. - NAGASHIMA, A. - SENGERS, V. J. 1991. Measurement of the transport properties of fluids. In Experimental Thermodynamics, London : Blackwell Scientific Publications. 1991

\section{Contact address:}

doc. RNDr. Monika Božiková, PhD; Slovak University of Agriculture in Nitra, Faculty of Engineering, Department of Physics, Tr. A. Hlinku 2, 94976 Nitra, Slovak Republic, e-mail: Monika.Bozikova@uniag.sk 